\title{
Edukasi literasi terhadap warga binaan pemasyarakatan membaca dan memahami kitab suci
}

\author{
Hasahatan Hutahaean', Sefendi², Luhut Sinaga ${ }^{3}$ \\ ${ }^{1}$ Sekolah Tinggi Teologi Sumatera Utara, Indonesia, email: hasea2014@gmail.com \\ ${ }^{2}$ Sekolah Tinggi Teologi Sumatera Utara, Indonesia, email: sefendi2019@gmail.com \\ ${ }^{3}$ Sekolah Tinggi Teologi Anugerah Sinagoge, Indonesia, email: luhutsinaga20@gmail.com \\ *Koresponden penulis
}

\section{Info Artikel}

Diajukan: 14 Des 2020

Diterima: 02 Mei 2021

Diterbitkan: 10 Mei 2021

Keywords:

$B G A$ training; encourages; lapas; understand the text

Kata Kunci:

pelatihan $B G A$;

menggiatkan; lapas;

pemahaman teks

\section{Lisensi:}

cc-by-sa

\begin{abstract}
This community service activity is aimed at the community assisted by the prison in Binjai Class II Lapas, Sumut. The situation that encourages the implementation of this activity is the large number of assisted residents who spend their free time just sitting and chatting. On the other hand, they are people who need guidance, be it moral, spiritual, and also training related to the needs of the community after going through the prison process. The method of activity is community development in prison. Activities carried out with training and group exercises. The material provided was then trained in each group. This community service activity takes a model of how to understand the text of the Bible in Christianity which is called Bible Digging (BGA). The BGA method is very simple and in its simplicity, it is believed to encourage Christians to live better lives in God and to pray diligently. The BGA training was finally able to motivate the assisted residents to read the Bible more actively and committed. Therefore, it is hoped that similar training can be adopted for Lapas or other communities to provide a better sense of well-being.
\end{abstract}




\section{PENDAHULUAN}

Warga Binaan Pemasyarakatan (WBP) akhir-akhir ini menjadi sorotan karena timbulnya berbagai masalah di dalam Lapas dan atau Rutan dipicu dari berbagai latar belakang. Misalnya pada April 2016 kebakaran Lapas di Banceuy Bandung diduga kuat karena kericuhan yang terjadi diantara WBP, khususnya WBP dengan kasus penyalahgunaan narkoba. Demikian juga kebakaran di Lapas Kelas III Langkat-Sumut, Mei 2019 terjadi akibat keributan antara WBP kasus narkoba dengan petugas Lapas yang menemukan adanya paket narkoba dari pengunjung. Kejadian-kejadian seperti ini tidak berhenti pada kebakaran saja tetapi juga berujung pada benturan fisik antar WBP atau antara WBP dengan petugas Lapas hingga adanya WBP yang melarikan diri dari Lapas/Rutan. Kasus rusuh lainnya masih banyak ditemukan di Lapas atau Rutan di Indonesia. Salah satu dari sekian banyak penyebab yang seringkali muncul di publik adalah melebihi kapasitas penghuni (Fajriando, 2019).

Sementara itu UU No. 12 tahun 1995 tentang Pemasyarakatan mengatur dengan jelas perihal pembinaan-pembinaan yang diberikan Negara kepada WBP selama menjalani hukuman atas kasus yang dilakukannya (Heliany \& Manurung, 2019). Adapun pembinaan itu diatur pada Bab II pasal 5 sampai dengan Pasal 9 dimana WBP menerima pembinaan dengan berbagai bidang. Baik itu keterampilan tangan (Melati et al., 2020) hingga cocok tanam dan tidak lupa literasi spiritualitas dari berbagai agama (Wardhini et al., 2020) yang ada di Indonesia. Rutan Labuhan Deli, kecamatan Labuhan Deli, Kodya Medan misalnya memberikan pembinaan cocok tanam di kawasan Marelan dan membuka cuci kendaraan (doorsmeer) tidak jauh dari lokasi Rutan. Sedangkan di Lapas Binjai WBP selain berbagai kerajinan tangan, Lapas juga memberikan lahan tanam hidrophonik di lahan sekitar Lapas.

Sejauh ini pembinaan demi pembinaan telah diupayakan di Lapas Binjai. Terutama pembinaan spiritualitas dan konseling diupayakan oleh Lapas bekerjasama dengan berbagai agama melalui Mesjid, Gereja, Vihara "Kelenteng" atau Lembaga-lembaga keagamaan yang ada. Pada umumnya pembinaan diberikan diantara pukul 09.00 hingga 12.00 WIB., sedangkan setelah makan siang diisi kegiatan-kegiatan bebas namun masih dalam lokasi Lapas tentunya.

Pada bagian lain dari kehidupan WBP di Lapas Binjai masih ditemukan di berbagai sudut kamar dan bangsal WBP duduk-duduk, bercengkerama satu sama lain meski kegiatan pembinaan dilakukan. Baik pembinaan dengan latar spiritualitas maupun pembinaan berupa pelatihan-pelatihan kerja, belum memberi daya tersendiri bagi WBP untuk mengikutinya. Padahal kesempatan untuk menempah keterampilan ataupun mendekatkan diri kepada Tuhan Yang Maha Esa sangat besar ketika WBP menjalani masa pembinaan di Lembaga Pemasyarakatan/ Lapas.

Melihat dari kondisi ini Prodi Teologi Sekolah Tinggi Teologi Sumatera Utara (STT-SU) mengambil sedikit usaha dengan menciptakan pelatihan yang bermanfaat bagi WBP Lapas Binjai. Seraya menyimak upaya yang menyatakan bahwa untuk meningkatkan kompetensi literasi tentu perlu upaya 
literasi di bidangnya (Setyaningsih et al., 2018). Khususnya dalam bidang pelatihan membaca, menggali Alkitab untuk kemajuan spiritualitas serta kemampuan memahami teks Kitab Suci melalui satu metode yang sederhana yang disebut Metode Baca Gali Alkitab (BGA). Metode ini telah berhasil di berbagai Gereja dalam mendorong jemaat untuk rajin membaca Alkitab dan berdoa secara pribadi ataupun berjemaah. Dalam studi Teologi di Sekolah Tinggi Teologi, BGA ini menjadi bagian dari ilmu tafsir yang disebut juga dengan Hermeneutika (Moules et al., 2016). Hermenutika sejatinya adalah upaya untuk menemukan pesan, makna dan maksud teks untuk diketahui dan dihidupi oleh orang Kristen agar semakin dekat kepada Allah dengan pemahaman yang benar dan melakukan firmanNya sehari-hari (Osborne, 2012).

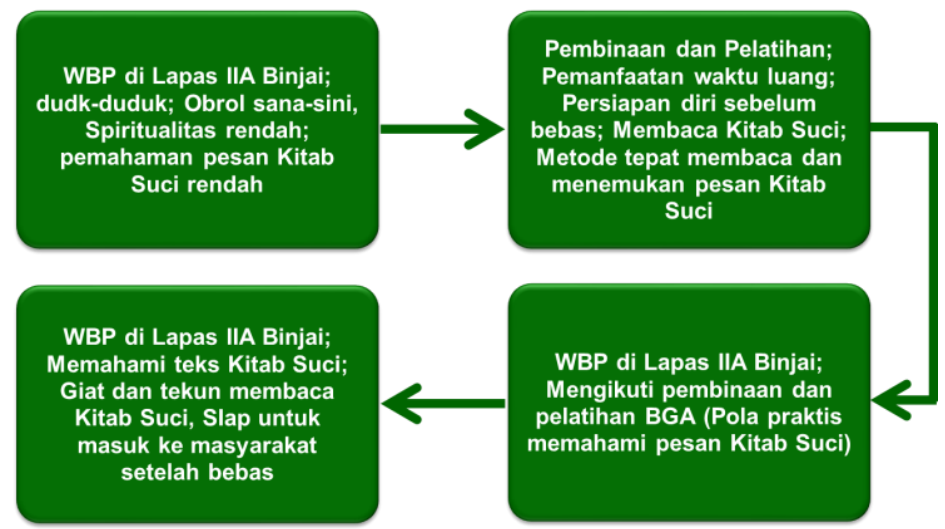

Gambar 1. Kondisi WBP dan Kebutuhan Pembinaan

Langkah-langkah dalam metode BGA merupakan cara yang sederhana untuk memahami teks dan yang tidak kalah penting adalah tuntutan agar orang yang membaca dan memahaminya agar memberikan action terhadap pemahaman yang ditemukan dalam bacaan hari itu. Dengan pelatihan literasi membaca ini diharapkan akan ada perubahan penambahan pengetahuan sehingga perubahan perilaku dari pemahaman pelatihan akan muncul (Band. Firmansyah et al., 2019). Melihat hal ini maka prodi Teologi membentuk Tim Pengabdian Masyarakat khusus untuk pengejewantahan Tri Dharma Perguruan Tinggi dengan mengambil lokasi Lapas Binjai, khususnya mendorong WBP kian dekat kepada Allah dan hidup dalam penyerahan penuh kepada Allah pencipta.

\section{METODE PELAKSANAAN}

Pengabdian Masyarakat ini berupa pelatihan membaca dan menggali Kitab suci untuk memahami teks dan mengetahui apa yang harus dikerjakan sebagai respons umat terhadap pesan nats. Metode yang digunakan berupa tahapan-tahapan dari perencanaan hingga evaluasi dan penyusunan laporan kegiatan dalam pengembangan kompetensi komunitas (Community Development) di Lapas, khususnya dalam bidang kemampuan memhami 
Kitab Suci. Setelah Tim Pengbabdian Masyarakat dibentuk kemudian dilakukan brainstorming ideas untuk menyamakan maksud, tujuan dan harapan dari giat dimaksud. Tim yang terbentuk yaitu; Sefendi, Luhut Sinaga dan Hasahatan Hutahaean. Tahap pertama yaitu merencanakan kegiatan dengan mengetahui masalah di masyarakat (dalam hal ini Lapas) dan kebutuhan yang dapat dipenuhi oleh Tim. Permasalahan yang ada dipersempit agar kegiatan yang direncanakan lebih terukur dan dapat tercapai. Tim melihat adanya WBP yang tidak menggunakan waktu dalam pengembangan diri di Lapas. Tim juga melakukan wawancara terhadap WBP tentang kebutuhan yang dirasa dalam bidang kerohanian Kristen. Sdr. Pangaribuan (WBP kasus $X$ ) mengatakan bahwa kemampuan WBP memahami makna kitab suci sangat rendah sehingga WBP banyak waktu kosong. Untuk menangkap pesan teks tidak saja dapat membaca namun kemampuan menemukan makna dari teks (Fatmasari \& Fitriyah, 2016). Hasil dari kedua segmen observasi ini menguatkan hasrat Tim bahwa upaya pelatihan bagaimana membaca kitab suci dengan mudah diyakini akan jadi stimulan untuk lebih dekat dengan Allah setiap hari.

Tabel 1. Tahap-tahap pelaksanaan

\begin{tabular}{|c|c|c|c|}
\hline Observasi & Perencanaan & Pelaksanaan & $\begin{array}{l}\text { Evaluasi dan } \\
\text { Laporan }\end{array}$ \\
\hline $\begin{array}{l}\text { 1. Melihat langsung } \\
\text { ke Lapas }\end{array}$ & $\begin{array}{l}\text { 1. Menentukan waktu } \\
\text { pelaksanaan }\end{array}$ & $\begin{array}{l}\text { 1. Dibuka dengan doa } \\
\text { 2. Pemaparan materi }\end{array}$ & $\begin{array}{l}\text { 1. Mengumpulkan } \\
\text { masukkan }\end{array}$ \\
\hline $\begin{array}{l}\text { 2. Wawancara } \\
\text { terhadap WBP }\end{array}$ & $\begin{array}{l}\text { 2. Mengumpulkan materi } \\
\text { yang dibutuhkan } \\
\text { 3. Menentukan topik } \\
\text { pelatihan dan } \\
\text { menentukan } \\
\text { narasumber } \\
\text { 4. Konfirmasi ke Lapas }\end{array}$ & $\begin{array}{l}\text { 3. Latihan peserta per } \\
\text { kelompok } \\
\text { 4. Diskusi kesan-pesan }\end{array}$ & $\begin{array}{l}\text { peserta } \\
\text { 2. Tabulasi usul } \\
\text { terbanyak } \\
\text { 3. Menyusun } \\
\text { laporan }\end{array}$ \\
\hline
\end{tabular}

Tahap kedua adalah perencanaan kegiatan. Pemilihan waktu, jumlah peserta dan konfirmasi ke pihak Lapas. Karena kegiatan ini berupa pelatihan maka peserta dibatasi agar latihan demi latihan dapat diberikan dan diawasi dengan seksama oleh Tim. Tahap ketiga adalah pelaksanaan kegaitan dimaksud dari awal hingga akhir. Tidak lupa setelah pelaksanaan diupayakan sesi mendengar kesan dan pesan peserta terhadap kegiatan dimaksud. Sedangkan tahap keempat yakni evaluasi kegiatan dan menyusun laporan. Meski kegaitan ini swadaya Tim Dosen dan Mahasiswa, namun laporan penggunaan keuangan tetap diberikan sebagaimana laporan kegiatan umumnya.

\section{HASIL DAN PEMBAHASAN}

Pelaksanaan pengabdian masyarakat selama empat hari berturut-turut tanggal. 5 sampai 8 Agustus 2019 di Lapas Kelas IIA Binjai, Sumatera Utara. Peserta dibatasi maksimal 40 orang saja dengan ketentuan tidak meninggalkan sesi selama empat hari. Setelah diberikan pemaparan disiplin peserta dan pembagian buku tulis, alat tulis serta bahan bacaan, kegiatan 
dimulai dengan menyanyi rohani dan doa pembukaan. Narasumber yang ditentukan oleh Tim yaitu Hasahatan Hutahaean.

Hari pertama dan kedua diberikan materi tentang bagaimana membaca dan memahami nats dari genre Narasi. Sedangkan hari ketiga dan keempat dari genre Surat Kiriman. Baca Gali Alkitab (BGA) adalah suatu cara membaca menggali Alkitab dengan sistem pendekatan induktif. Pendekatan induktif ini dimaksud untuk mendapatkan makna/kebenaran Alkitab yang sesuai dengan teks dan konteks Alkitab. Seseorang mengeksegesis dan mengekspos ayat-ayat Alkitab dan diterapkan dalam kehidupan zaman sekarang. Dengan ber-BGA, seseorang akan bisa menafsir Alkitab dengan tidak ngawur/sembarangan, karena dengan BGA akan bisa melihat fakta yang tertulis pada teks Alkitab yang sesuai dengan konteks Alkitab pada waktu itu. Hasil dari upaya tersebut akan mampu membahasakan Alkitab dari budaya dahulu kepada hidup kita pada zaman ini.

Hari pertama disampaikan bagaimana metode BGA itu sesungguhnya. Dengan memperhatikan bukan Panduan (Barus et al., 2015) yang dikeluarkan oleh Lembaga Pelayanan yang menaungi dan memberikan pelayanan ini. Sebagai satu buku (kitab = kumpulan tulisan, buku), Alkitab terdiri dari berbagai tulisan yang mempunyai ciri dan jenis (genre) masing-masing. Tentu untuk memahami tulisan-tulisan dengan genre berbeda, dibutuhkan metode yang berbeda pula. Prinsip ini berlaku juga bagi tulisan lain diluar Kitab Suci, bahwa pemahaman jenis tulisan akan menolong pembaca untuk menentukan cara pendakatan terhadapnya agar memperoleh makna teks yang sebenarnya (Boell \& Cecez-Kecmanovic, 2014).

Pada hari pertama setelah penjelasan metode BGA secara umum, narasumber memberikan pemaparan metode untuk memahami teks genre Narasi. Untuk ini digunakan juga buku panduan yang telah dipersiapkan (Barus, 2019). Genre narasi adalah genre terbanyak dalam Alkitab. Diperkirakan hampir 2/3 Alkitab terdiri dari genre narasi (Teeter, 2013). Prinsip untuk memahami narasi diantaranya pertama, menemukan tokoh-tokoh yang ada dalam teks. Kemudian menemukan waktu dan tempat saat teks itu ada. Meski demikian, tidak semua teks yang digali mengandung ketiga bagian ini. Setelah menemukan tokoh, tempat dan waktu, maka perlu untuk menuliskan kembali dengan bahasa sendiri. Guna menemukan pesan teks, langkah yang diberikan oleh metode BGA adalah membantu pembaca Alkitab dengan lima jenis pesan yakni; pelajaran, peringatan, perintah, teladan dan janji. Demikian juga pada bagian penemuan pesan agar tidak memaksakan untuk memberi pesan dari kelima jenis pesan dimaksud. Karena adakalanya satu perikop atau teks memberikan pesan pada jenis perintah dan janji, bisa juga teladan dan peringatan. Karena itu perlu panduan yang hati-hati kepada peserta guna memahami langkah-langkah BGA serta memberikan latihan untuk memastikan pemahaman peserta.

Hari kedua dipenuhi dengan latihan peserta yang telah dibagi menjadi enam kelompok. Masing-masing diberi nats dari genre narasi diberikan waktu 45 menit kerja kelompok, setelah itu presentase hasil kerja kelompok. Pada saat presentase ini masing-masing kelompok boleh mengajukan pertanyaan 
kepada kelompok yang sedang presentase untuk memperoleh kejelasan atau pendalaman makna.

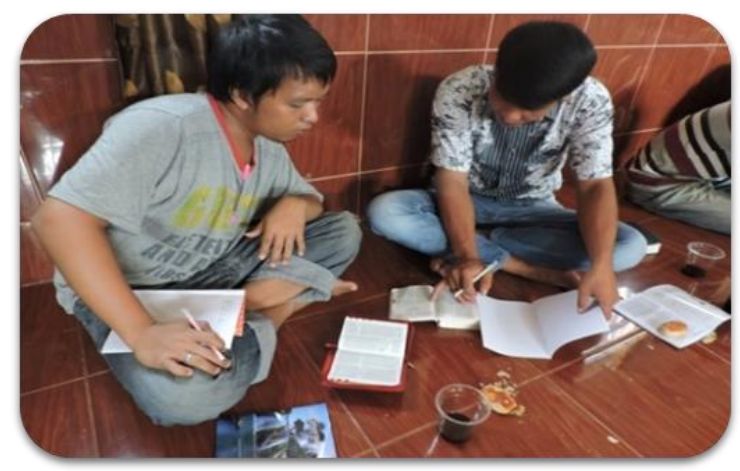

Gambar 2. Proses Latihan Kelompok

Pada hari ketiga materi beralih kepada genre Surat Kiriman. Untuk ini bahan telah dipersiapkan (Hutahaean, 2017) serta kelompok-kelompok latihan yang sama dengan hari sebelumnya. Setelah dipaparkan bagian-bagian yang perlu perhatian untuk membaca dan menggali genre Surat Kiriman, narasumber mencoba memberi latihan dari Surat Roma. Prinsip pemahaman teks genre Surat Kiriman diantaranya; pertama bahwa surat kiriman adalah komunikasi antara pengirim dan penerima pertama. Kedua, dari sisi isi bisa berupa klarifikasi teologis, kadang kala berisi pujian dan doa kepada penerima surat, ada juga berisi pemaparan teologis tentang Kristus. Terdapat juga ada surat kiriman yang menyinggung kepada pemberian maaf dan menerima kembali orang yang pernah bersalah (Surat Filemon). Pada genre Surat Kiriman interaksi antar tokoh tidak perlu digali seperti pada genre Narasi (Ruiz, 2017). Namun penggalian pesan dan aplikasi Surat Kiriman dan Narasi memiliki kesamaan jenis dan prinsip.

Pada hari keempat diberikan kesempatan berlatih di kelompok masingmasing dengan memilih nats-nats dari genre Surat Kiriman dalam Alkitab. Kemudian dipersilahkan presentasi kelompok dengan mengijinkan kelompok lain untuk mengajukan pertanyaan atau mendalami makna teks.

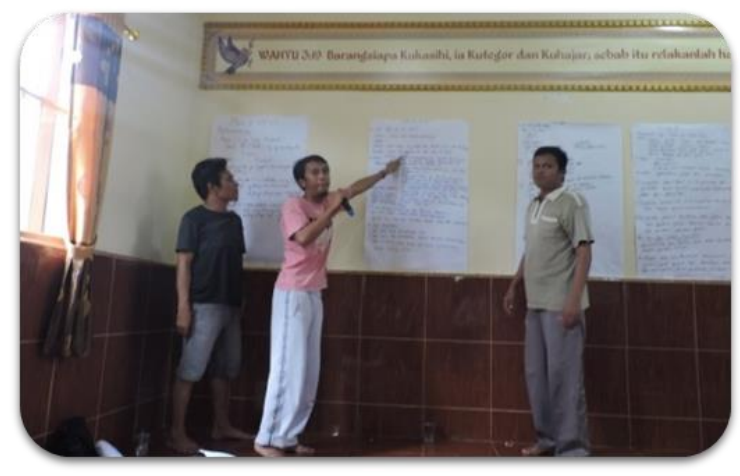

Gambar 3. Presentasi Kelompok 
Pertanyaan-pertanyaan yang muncul dari peserta umumnya tentang kesulitan untuk menemukan pesan. Sebab WBP beranggapan jika salah menemukan pesan maka salah dalam pemaknaan teks. Hal ini akan berbuntut pada kesalahan dalam aplikasi sehari-hari. Pertanyaan demi pertanyaan dijawab narasumber dengan lugas dan bahasa yang mudah dipahami oleh WBP. Tampak wajah peserta antusias dan puas dengan jawaban yang diberikan.

Sebelum akhir dari kegiatan selama empat hari, diadakan kesan dan pesan dari peserta. Seorang peserta berterima kasih kepada Tim karena memberikan wawasan baru tentang bagaimana memahami Kitab Suci dengan sederhana. WBP tersebut berharap agar peserta lainnya mau bersama-sama untuk menggunakan waktu luang yang ada kepada kegiatan-kegiatan yang berguna seperti pelatihan yang diikuti empat hari. Apalagi kegaitan pelatihan ini berhubungan dengan kerohanian. Peserta lainnya memberi apresiasi yang mendalam juga kepada Tim yang dengan sabar memberikan pendampingan selama latihan dalam kelompok. Sehingga materi yang diperoleh bisa dipergunakan saat berlatih kelompok. Usaha pendampingan kepada WBP yang telah jauh dan sangat lama dengan kegiatan pembelajaran itu sungguh menyentuh peserta. Sehingga masing-masing peserta mampu untuk menemukan pesan teks Kitab Suci. Pertemuan diakhiri dengan bernyanyi rohani dan doa penutup oleh salah seorang peserta.

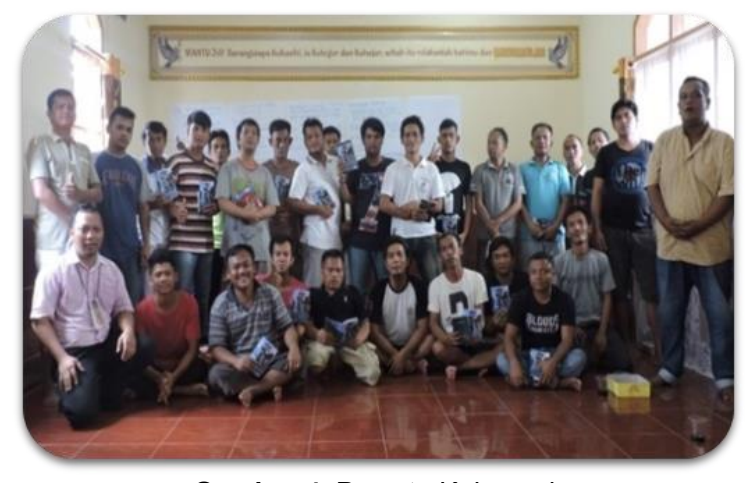

Gambar 4. Peserta Kelompok

Dari aktifitas peserta yang mengikuti pelatihan tampak bahwa metode BGA mampu menstimulan gairah untuk membaca dan mencari tahu makna teks kitab Suci. Jika kegaitan ini menjadi bagian ritmen kehidupan WBP di dalam Lapas tentu memberi warna yang beda ke depannya. Baik dalam Lapas maupun setelah WBP keluar/bebas dari masa penahanannya. Dengan demikian diharapkan ada pertumbuhan iman dalam diri WBP ke depan. Cara ber-BGA yang praktis adalah mengajak membaca nats yang sudah dipersiapkan, menggalinya secara mandiri, menemukan pesan dan didorong untuk memberikan komitmen aplikasi (action) atas pesan yang ditemukan. Lalu menceritakan ulang tentang nats yang dibaca, apa yang tertulis dalam 
nats itu, kepada orang lain akan membuat makna firman TUHAN lebih terlaksana.

Kegiatan ini pula yang dapat menjadi solusi bagi habitus WBP di dalam Lapas selama menjalani masa penahanan. Kehidupan dalam Lapas menjadi berariasi dan bermanfaat bagi pertumbuhan spiritualitasnya. Sebagai seorang narapidana, habitus ini tentu menggembirakan sebab sarana pertobatan telah dibangun melalui pelatihan BGA. Dengan pertumbuhan spiritualitas yang baik, akan mengurangi tingkat kekuatiran Negara yang diwakilkan oleh pelaksana penjaga Lapas.

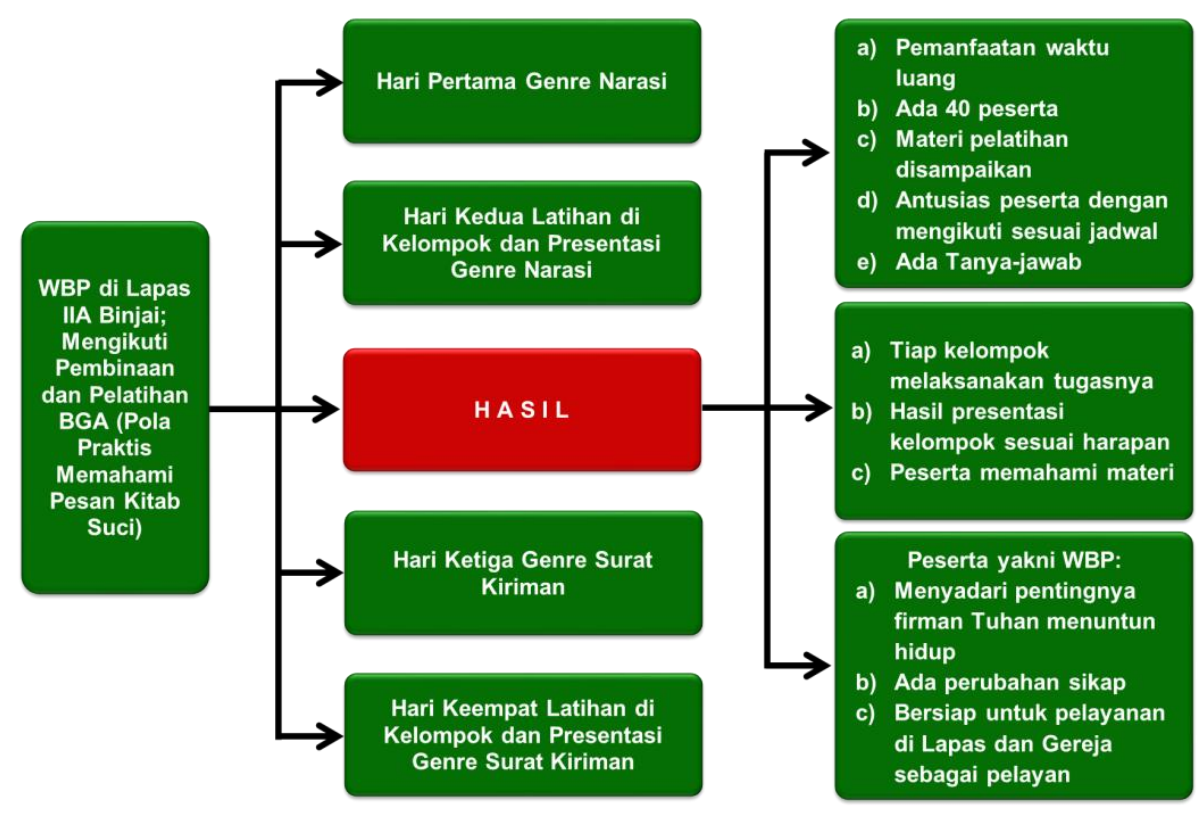

Gambar 5. Hasil Pelaksanaan

Kegiatan ini juga diharapkan menjadi referensi bagi Lapas lainnya bahkan bagi Kemenhumkam khususnya direktorat jenderal pemasyarakatan guna mengurangi potensi konflik dan kerusuhan di Lapas. Tentu jika kerohanian WBP semakin baik, hidup keagamaannya semakin benar karena menemukan makna Firman Tuhan dengan benar, diyakini akan mengubah pola berpikir, bertindak dan pola berbicara WBP sesama umat kristen dan juga kepada WBP non kristen lainnya. Karena itu proses asimilasi dan pemasyarakatan pada menjelang masa pidana akan lebih mudah. Tidak sampai disitu, tentu keluarga yang telah ditinggalkan sekian lama juga memperoleh manfaat dari perubahan sikap dari WBP ketika bebas/habis masa tahanannya. Karena perangai dan hidupnya berubah drastis sebelum menjalani pidana dibanding setelah bebas dari Lapas. Tentu pemandangan ini dirindukan oleh semua keluarga yang memiliki sanak menjalani masa penahanan di Lapas, yakni perubahan drastis dari cara hidup lama kepada cara hidup baru dalam spiritualitas yang bertumbuh dengan baik dan benar. Inilah manfaat BGA bagi segmen masyarakat WBP. 


\section{KESIMPULAN}

Pengabdian masyarakat ini merupakan kebutuhan di tengah masyarakat, bangsa dan Negara khususnya di lingkup WBP. Untuk itu harapannya agar kegiatan dimaksud dapat dilaksanakan di Lapas lainnya guna memetik hasil yang positif bagi lingkup Lapas dan juga lingkup keluarga yang menantikan masa bebas WBP kelak. Waktu pelaksanaan pada pkl.14.00 hingga 17.00 WIB menjadi tantangan tersendiri selama pelatihan. Sebab waktu seperti ini sering juga disebut dengan "jam rawan." Yakni saat dimana rasa kantuk itu menerpa peserta. Keterbatasan dari kegiatan lainnya adalah jenjang pendidikan dan kemampuan menangkap materi yang tidak merata. Hal ini dapat dimengerti sebab WBP berasal dari berbagai daerah, umur, suku, latar pendidikan dan juga durasi WBP yang menempati Lapas juga berbeda. Namun demikian perlu menggalakkan kegaitan ini agar semakin banyak orang memberi hormat dan tunduk kepada Allah Penciptanya dan hidup bergantung kepadaNya (Hutahaean, 2020). Baik masyarakat di dalam dan di luar Lapas.

Karena itu untuk kegiatan serupa selanjutnya agar memilih waktu yang lebih baik, guna membuat peserta lebih siap mengikuti pelatihan. Misalnya di pagi hari agar lebih kuat dan segar secara fisik. Kegiatan sama hendaknya dapat dilaksanakan sebanyak mungkin agar lebih banyak lagi WBP mengalami pertumbuhan spiritual melalui pemahanan membaca, menggali dan menemukan makna Firman Tuhan.

\section{UCAPAN TERIMA KASIH}

Terima kasih disampaikan kepada KaLapas Kelas II Binjai, Bapak Maju Siburian yang telah mengijinkan terlaksananya kegiatan ini. Demikian juga bantuan kop, teh dan snack dari Scripture Union Indonesia untuk dinikmati peserta selama kegaitan berlangsung. Tim ini tentu akan melanjutkan banyak kegiatan lainnya untuk kemajuan literasi Kitab Suci, demi anugerahNya dan dari kemurahanNya.

\section{DAFTAR RUJUKAN}

Barus, A. (2019). Panduan Bagi Fasilitator Baca Gali Alkitab Genre Narasi (R. A. Santoso (ed.)). Scripture Union Indonesia.

Barus, A., Wuysang, H., \& Panjaitan, R. (2015). Panduan Pelatihan Baca Gali Alkitab. Scripture Union Indonesia.

Boell, S. K., \& Cecez-Kecmanovic, D. (2014). A hermeneutic approach for conducting literature reviews and literature searches. Communications of the Association for Information Systems, 34(1), 257-286. https://doi.org/10.17705/1cais.03412

Fajriando, H. (2019). Evaluasi Pelaksanaan Community-Based Corrections di Lapas Terbuka Kelas III Rumbai. Jurnal IImiah Kebijakan Hukum, 13(3), 323-338. https://doi.org/10.30641/kebijakan.2019.v13.323-338

Fatmasari, R. K., \& Fitriyah, H. (2016). Keterampilan Membaca. In Sakrim (Ed.), Dampak Rendahnya Minat Baca Dikalangan Mahasiswa Pgsd Lampeuneurut Banda Aceh Serta Cara Meningkatkannya. STKIP 
PGRI Bangkalan.

Firmansyah, A., Arham, A., \& M. Elvin Nor, A. (2019). Edukasi Akuntansi dan Bimbingan Teknis Penyusunan Laporan Keuangan Usaha Mikro, Kecil, dan Menengah. Wikrama Parahita: Jurnal Pengabdian Masyarakat, 3(2), 57-63. https://doi.org/10.30656/jpmwp.v3i2.1766

Heliany, I., \& Manurung, E. H. (2019). Sistem Pembinaan Narapidana di Lembaga Pemasyarakatan Klas I Cipinang Ditinjau Berdasakan Undang-Undang No 12 Tahun 1995 Tentang Pemasyarakatan. In Tim Universitas Trisakti (Ed.), Prosiding Seminar Nasional Cendekiawan. Lembaga Penelitian Universitas Trisakti. https://doi.org/10.25105/semnas.v0i0.5848

Hutahaean, H. (2017). Pengantar Memahami Surat Roma Dengan Baca Gali Alkitab. Cultivation, 1(2), 216-230.

Hutahaean, H. (2020). Pelayan Tuhan di Gereja dan Masyarakat. Pustaka Star's Lub.

Melati, I. S., Margunani, M., Mudrikah, S., \& Pitaloka, L. K. (2020). Upaya Optimalisasi Praktik Digital Marketing UNtuk Meningkatkan Hasil Penjualan Produk Wrga Binaan Lembaga Pemasyarakatan. Panrita Abdi - Jurnal Pengabdian Pada Masyarakat, 4(2), 155-163. https://doi.org/10.20956/pa.v4i2.7685

Moules, N. J., McCaffrey, G., Field, J. C., \& Laing, C. M. (2016). Conducting Hermeneutic Research. In N. J. Moules (Ed.), Conducting Hermeneutic Research. Peter Lang linternational Academy Publisher. https://doi.org/10.3726/978-1-4539-1473-1

Osborne, G. R. (2012). Spiral Hermeneutika: Pengantar Komprehensif bagi Penafsiran Alkitab. Momentum.

Ruiz, G. A. (2017). Examining the Role of the Reader: A Necessary Task for Catholic Biblical Interpretation. Horizons, 44(1), 28-55. https://doi.org/https://doi.org/10.1017/hor.2017.1

Setyaningsih, R., . A., \& Asy'ari, N. A. S. (2018). Pemberdayaan Mahasiswa sebagai upaya untuk Meningkatkan Kemampuan Literasi Media Masyarakat di Karesidenan Madiun. Jurnal Pengabdian Masyarakat Universitas Merdeka Malang, 2(2), 51-56. https://doi.org/10.26905/abdimas.v2i2.1817

Teeter, D. A. (2013). On Exegetical Function in Rewritten scripture: InnerBiblical Exegesis and the Abram/Ravens Narrative in Jubilees. In Harvard Theological Review (Vol. 106, Issue 4, pp. 373-402). Cambridge University Press. https://doi.org/10.1017/S0017816013000217

Wardhini, S. R., K.W, R. W., \& Pasiska, P. (2020). 'Masuk Napi Keluar Santri': Pembinaan Narapidana Berbasis Pesantren di Lapas Kelas II A Kota Lubuklinggau. Psychosophia: Journal of Psychology, Religion, and Humanity, 2(2), 111-125. https://doi.org/10.32923/psc.v2i2.1453 